\title{
Diagnostic Accuracy of Elastography in Differentiating Benign from Malignant Thyroid Nodules Taking Fine Needle Aspiration Cytology as Gold Standard
}

\author{
Ameet Jesrani, Marya Hameed, Naveed Ahmed, Pooja Devi, Abdul Baseer

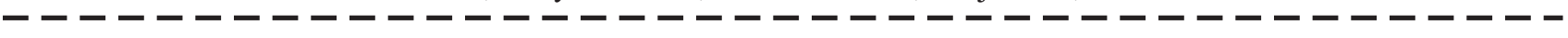 \\ ABSTRACT
}

Objective: To evaluate the diagnostic accuracy of Strain Elastography in differentiating benign from malignant thyroid nodules taking fine needle aspiration cytology as gold standard.

Study Design and Setting: It was a cross sectional study conducted at Radiology department of Jinnah Postgraduate Medical Centre, Karachi from May 2019 to June 2020

Methodology: Total 586 patients with complaints of swelling in region of thyroid gland were enrolled in study on which Strain Elastography was performed using linear transducer with ultrasound frequency of $7.5 \mathrm{MHz}$. The results of strain Elastography were compared with histopathology. All the information was recorded into predesigned proforma. Chi-square test was used for comparison among categorical variables and when it has not worked then imitation of Monte Carlos was applied and to see agreement among various categorical variables Kappa statistics were performed. Level of statistical significance was accepted as $P<0.05$.

Results: The sensitivity of $100 \%$, specificity of $80.2 \%$, positive predictive value of $61.7 \%$, negative predictive value of $100 \%$, and diagnostic accuracy of $85 \%$ of elastography was calculated in differentiation among benign from malignant thyroid nodules.

Conclusion: Strain elastography is noninvasive technique which can be used to characterize thyroid nodules and helps in differentiating benign from malignant thyroid nodules and can limit the utilization of invasive technique like FNAC and helps in selection of patients which needs surgery.

Keywords: Benign, Histopathology, Malignant, Noninvasive imaging, Strain Elastography, Thyroid Nodules

How to cite this Article:

Jesrani A, Hameed M, Ahmed N, Devi P, Baseer A. Diagnostic Accuracy of Elastography in Differentiating Benign from Malignant Thyroid Nodules Taking Fine Needle Aspiration Cytology as Gold Standard. J Bahria Uni Med Dental Coll. 2021; 11(2):70-75 DOI: https://doi.org/10.51985/OLBL1894

This is an Open Access article distributed under the terms of the Creative Commons Attriution Non Commercial Liciense (http:// creativecommons/org/licences/by-nc/4.0) which permits unrestricted non commercial use, distribution and reproduction in any medium, provided the original work is properly cited.

- - - - - - - - - - - - - - - - - - - - - - - - - - -

\section{INTRODUCTION:}

Nodules in thyroid gland are widespread and present as solid or cystic lumps in the population and are predominantly non-cancerous and sometimes as cancerous nodules. Depending on the populace and the approach used, its occurrence will vary and reports are showing increasing - - - - - - - - - - - - - Ameet Jesrani

Assistant Professor, Department of Radiology

Sindh Institute of Urology and Transplantation, Karachi

I Email: ameet.jesrani@yahoo.com

I Marya Hameed

I Consultant Radiologist, Department of Radiology

I Jinnah Postgraduate Medical Centre, Karachi

I Naveed Ahmed

I Consultant Radiologist, Department of Radiology

I

Pooja Devi

Resident, Department of Radiology

I Sindh Institute of Urology and Transplantation, Karachi

Abdul Baseer

I Resident, Department of Radiology

I Sindh Institute of Urology and Transplantation, Karachi

I Received: 28-10-2020

Accepted: 16-03-2021 trend in their prevalence. ${ }^{1}$ Nodule occurrence increases with age and is increased in women, in human beings with iodine deficiency, and after radiation exposure to head and neck. Some reports showing that their prevalence vary in accordance with physical examination they noted in 2 to $6 \%$ of population, in $4-8 \%$ by palpation method in adults, while by ultrasonography they noted in 10 to $41 \%$ of population and on data of autopsy their prevalence is $50 \%$ (8 to $65 \%$ ). ${ }^{[2]}$ Cytology/histopathology must be performed before surgery to diagnose thyroid nodules and distinguish between benign and malignant nodules. High-resolution thyroid ultrasound and real-time elastography are adjuvant presurgical tools in selecting patients for surgery, particularly those with uncertain or non-diagnostic cytology. ${ }^{1}$

Elastosonography is a new advanced dynamic approach that can estimate the hardness of tissues by ultrasound (US). This is achieved by measuring the degree of deformation under the action of external forces. This technique is based on the following principle: when compressing body tissue, the softer parts are more likely to deform than the hard parts. Strain US elastography technique is based totally on lowfrequency compression of the tissue, that is typically implemented manually through the handheld ultrasound 
transducer (additionally referred to as freehand EUS).The principal precept of strain EUS is based on a compressive force applied to tissue inflicting axial tissue displacement. Tissue stiffness is calculated by way of comparing the echo sets earlier than and after the compression. Ultrasound elastogram is displayed on the B mode image in a color scale that tiers from red for components with the greatest elastic strain (i.e. the softest component), to blue for components without elastic strain (the hardest component). ${ }^{2}$ Currently nodules in thyroid gland are assessed by comparing the elasticity in tissues by method called Elastography. ${ }^{3}$ The two kinds of elastography being utilized in scientific practice are Strain and Shear wave elastography (SWE). ${ }^{4}$ Strain elastography can evaluate two kinds of elasticity, first, according to the 4-5 scoring system and secondly there is visual scoring by color coding in the nodules and around the nodules. Second, the area of interest is designated as the target area and the adjacent reference area. After that, the strain ratio is automatically calculated by elastography.

A higher strain ratio leads to a higher probability of malignancy. ${ }^{4} \mathrm{SWE}$ can obtain a quantitative elastic value based on stimulus of tissue by sound waves. So nodules in thyroid gland can be evaluated by acoustic radiation and shear wave techniques by ultrasonography. ${ }^{5}$ Strain elastography is used to characterize thyroid nodules. ${ }^{6}$ They are very common in population and are found in $50 \%$ of ultrasound examinations. Most nodules are benign, with approximately $5 \%$ to $10 \%$ of malignancy. ${ }^{6}$ Firm or hard consistency upon palpation is associated with an increased risk of malignancy as reported in recent consensus. ${ }^{7}$ Fine needle aspiration cytology (FNAC) is the best single test for differentiating malignant from benign thyroid lesions. The major limitation of FNAC is that $10 \%$ to $15 \%$ of specimens are non-diagnostic or indeterminate. In addition, there are reports that the elastography technique to evaluate the stiffness of nodules has recently been put into practice. It overcomes the limitations of traditional Color Doppler and Gray scale sonography and improves specificity, so it is expected to be used to identify malignant lesions. ${ }^{8}$ Due to subjective interpretation, strain elastography provides operator-related results, while SWE is operator-independent; however, the verification of this method requires further research. ${ }^{6}$ After Rago et al., ${ }^{9}$ proposed use of noninvasive elastography as a latest technology for diagnosing thyroid cancer in 2007. These evaluation methods are based on the use of different scoring systems. The FNAB results of thyroid nodules or different patient groups were evaluated by pathological comparison of elastography. ${ }^{10,11,12,13,14}$

The rationale of this study is to highlight the use of new technique along with its advantages as noninvasive technique in evaluation of thyroid nodules demonstrate the availability, advantages, and predictive values of noninvasive strategies like strain elastography and to confirm cytology as to reduce the number of patients who need to refer to invasive diagnostic methods or who might go through surgical operation. Therefore; this study was aimed to evaluate the diagnostic accuracy of Strain Elastography in differentiating benign from malignant thyroid nodules taking fine needle aspiration cytology as gold standard.

\section{METHODOLOGY:}

This study was done from May 2019 to June 2020 in radiology department of Jinnah Postgraduate Medical Centre, Karachi. Total 586 patients by nonprobability consecutive sampling technique with complaints of swelling in region of thyroid gland were included. Age of patients was ranged from 25 to 65 years with mean age $35.5+10$ years of both genders referred from Outpatient Department of ENT clinics. Complete clinical evaluation and necessary laboratory investigations like $\mathrm{CBC}$, Thyroid profile including ( $\mathrm{T} 3, \mathrm{~T} 4$, and TSH levels) PT, APTT and INR were carried out. All those patients were excluded who did not show will for biopsy or left the hospital against medical advice or referred to other hospital. Considering sensitivity and specificity of strain elastography to diagnose benign and malignant thyroid nodules sample size was calculated in this cross sectional study after taking informed consent from ethical committee department.

Various characteristics of 586 nodules were evaluated in this study like their size, halo, echogenicity pattern and calcifications were noted on both Color Doppler with Elastography and gray sale ultrasonography by using (TOSHIBA; GRE, Germany) ultrasound machine with high frequency $(7.5 \mathrm{MHz})$ linear array transducer. Evaluation done by senior radiologist having more than 5 years of experience and was unaware of fine needle aspiration cytology results.

Four patterns were evaluated and so as nodules were categorized by elastography. When whole of the nodule has softer areas as tissue strain in comparision with surrounding tissue, it is labelled as pattern 1 . When a nodule has almost softer areas while fewer harder areas (coded blue), it is labelled as pattern 2. Pattern 3 labelled when most of the nodule has harder areas and pattern 4 when almost whole of the nodule has harder areas (coded blue) as compared to surrounding tissue values. FNAC was done which evaluated 444 nodules as benign and 142 as malignant. In order to obtain sensitivity and specificity of strain elastography for thyroid nodules SPSS 21.0 was statistically used. Frequency and percentage was calculated for qualitative variables like complains of patients, elastography and fine needle aspiration cytology findings frequency and percentages were calculated.

For quantitative variable like age of the patient mean $+\mathrm{SD}$ was computed. Sensitivity, specificity, PPV, NPV were calculated to obtain diagnostic accuracy of strain elastography taken fine needle aspiration cytology findings as gold standard. Chi-square test was used for comparison among categorical variables and when it has not worked then 
imitation of Monte Carlos was applied and to see agreement among various categorical variables Kappa statistics were performed. Level of statistical significance was accepted as $P<0.05$.

\section{RESULTS:}

Various features are demonstrated in Table 1 and Table 2 of both malignant and benign thyroid nodules like in terms of size there was no significant difference noted while features like hypoechogenecity, microcalcifications and absent halo was more pronounced in malignant thyroid nodules. Similarly the pattern 4 of elastography and central vascularity were more highlighting the presence of malignancy in nodules.

Hypoechogenecity, microcalcifications, absent halo and central vascularity increases the chances to be malignant by 3.8, 7.7, 11.5 and 5.8 times respectively, Table 2.

Figure 1 is showing almost complete harder area (blue) in thyroid nodule which is highly suggestive of malignant thyroid nodule. FNAC was done which showed solid sheets and nests of atypical cells, features of medullary carcinoma of thyroid gland.

Figure 2 is showing most of the area in thyroid nodule is green to very lighter blue and specks of reddish areas as

Table 1: Features of malignant and benign thyroid nodules

\begin{tabular}{|c|c|c|c|}
\hline $\begin{array}{c}\text { Characteristics of } \\
\text { nodule }\end{array}$ & $\begin{array}{c}\text { Benign } \\
\text { nodule } \\
(n=444)\end{array}$ & $\begin{array}{c}\text { Malignant } \\
\text { nodule } \\
(n=142)\end{array}$ & $P^{*}$ \\
\hline Nodule size & $24(5-70)$ & $26(3-45)$ & \\
\hline Presence of halo & & & \multirow{3}{*}{$<0.001$} \\
\hline No & $96(21.6)$ & $108(76.1)$ & \\
\hline Yes & $348(78.4)$ & $34(23.9)$ & \\
\hline $\begin{array}{l}\text { Presence of } \\
\text { microcalcification }\end{array}$ & & & \multirow{3}{*}{$<0.001$} \\
\hline No & $392(88.3)$ & $70(49.3)$ & \\
\hline Yes & $52(11.7)$ & $72(50.7)$ & \\
\hline Echogenicity & & & \multirow{3}{*}{$<0.001$} \\
\hline Isoechoic & $158(35.6)$ & $18(12.7)$ & \\
\hline Hypoechoic & $286(64.4)$ & $124(87.3)$ & \\
\hline Doppler patterns & & & \multirow{7}{*}{0.013} \\
\hline No remarkable & $56(12.6)$ & $6(4.2)$ & \\
\hline Vascularity & & & \\
\hline Peripheral vascularity & $146(32.9)$ & $38(26.8)$ & \\
\hline Peripheral+central & $168(37.8)$ & $52(36.6)$ & \\
\hline Vascularity & & & \\
\hline Central vascularity & $74(16.7)$ & $46(32.4)$ & \\
\hline Elastography & & & \multirow{5}{*}{$<0.001$} \\
\hline Pattern 1 & $26(5.9)$ & 0 & \\
\hline Pattern 2 & $330(74.3)$ & 0 & \\
\hline Pattern 3 & $88(19.80$ & $64(45.1)$ & \\
\hline Pattern 4 & 0 & $78(54.9)$ & \\
\hline
\end{tabular}

*Chi square test well (softer areas mostly) which signifies the findings as most likely of benign thyroid nodule. FNAC was done which showed closely packed follicles devoid of colloid and surrounded by thick capsule, features of benign follicular adenoma. Table 3 and Table 4 showing distribution of thyroid nodules and statistical analysis respectively. Figure 1: Strain elastography showing almost complete harder area (blue) in thyroid nodule which is highly suggestive of malignant nodule which is proved by FNAC (High-power view showing a neoplastic lesion composed of solid sheets and nests of atypical cells separated by richly vascularized stroma, in a case of medullary carcinoma of thyroid gland. (HE, $\times 200)$.

Figure 2: Strain elastography showing almost complete softer areas (green, very light blue and specks of red areas) which are highly suggestive of benign nodule which is proved by FNAC (Low-power view showing neoplastic lesion of thyroid composed of closely packed follicles devoid of colloid and surrounded by thick capsule. Surrounding compressed thyroid tissue is seen. Features are of follicular adenoma of thyroid. (HE, $\times 40$ ).

\section{DISCUSSION:}

Ultrasound examination is the main diagnostic tool for detecting and examining thyroid nodules.

According to reports, Doppler ultrasound is has high sensitivity in differentiating benign from malignant thyroid nodules $^{6}$ and some features like absent halo, microcalcifications, hypoechogenicity, irregular borders, and growth patterns of the mass, with anterior and posterior greater than medial-lateral increases likelihood. According to reports, these features detectable through the ultrasound are sensitive, but not specific enough. ${ }^{6}$ It was pointed out that in thyroid malignancy stiffness in nodules is an independent predictor. ${ }^{7}$

Evaluation by elastography becomes challenging when there is difference of opinion among interobservation among interobservers. Such type of variability was pointed out by Ko et al ${ }^{15}$ when he observed that physicians with lack of experience and those with good experience have difference of opinion among them in evaluating difference between benign and malignant thyroid nodules by elastography and reported that experienced physicians have higher specificity in such cases. In another study, for the consistency between observers, Cantisani et al. ${ }^{16}$ reported the Coen Kappa coefficient $(0.95)$ with the highest strain ratio measurement and the Cohen Kappa coefficient (0.83) with the lowest echogenicity score. There was a study conducted by Ragazzoni et al. ${ }^{17}$ who observed good agreement among three different operators and that was (kappa test: $0.64, \mathrm{P}$ $<0.0001)$. In this study, the two examiners' scores were almost perfect compared to the final score (the first examiner's kappa value was 0.835 , and the second examiners' kappa value was 0.815 ).

Various studies have been conducted on elastography for evaluation of thyroid nodules, one such study ${ }^{18}$ has shown 
Table 2: Risk factors for malignancy; OR: Odds ratio, CI: Confidence interval

\begin{tabular}{|l|c|c|c|c|}
\hline & \multirow{2}{*}{} & P & OR & \multicolumn{2}{|c|}{ 95\% CI } \\
\cline { 5 - 5 } & & & Lower limit & Upper limit \\
\hline Echogenicity (hypoechoic) & $<0.001$ & 3.806 & 1.796 & 8.066 \\
\hline Presence of microcalcification & $<0.001$ & 7.754 & 4.173 & 14.407 \\
\hline Absence of halo & $<0.001$ & 11.515 & 6.121 & 21.660 \\
\hline Doppler pattern (no remarkable vascularity) & 0.018 & & & \\
\hline Peripheral vascularity & 0.179 & 2.429 & 0.667 & 8.854 \\
\hline Peripheral = Central vascularity & 0.101 & 2.889 & 0.812 & 10.280 \\
\hline Central vascularity & 0.008 & 5.802 & 1.582 & 21.276 \\
\hline
\end{tabular}

Figure 1:
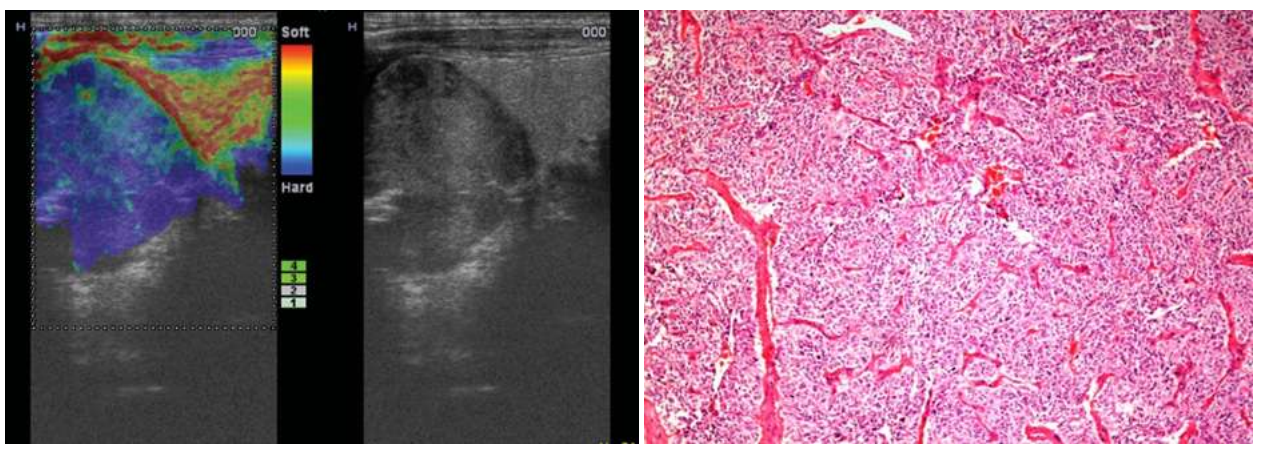

Figure 2:
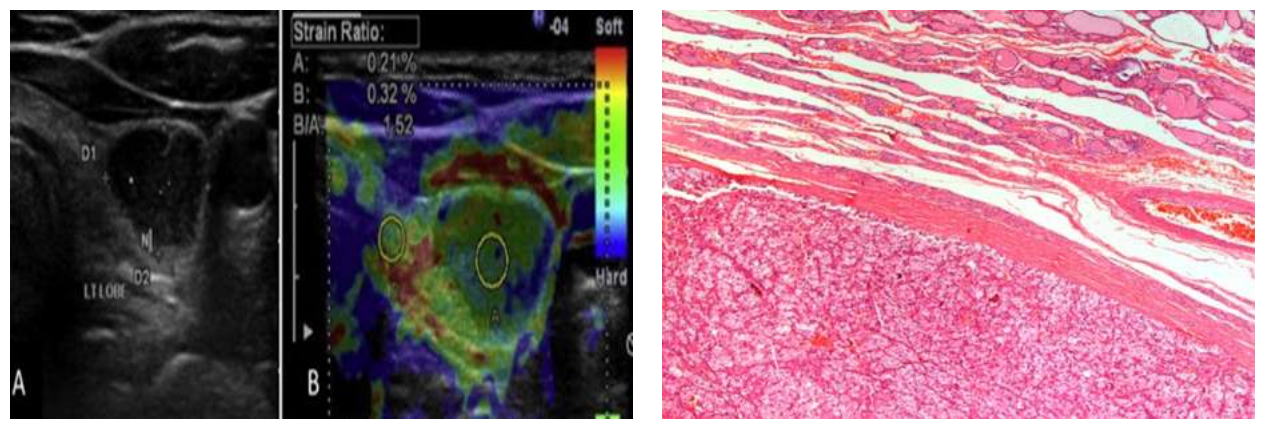

Table 3: Elastographic characterization of benign and malignant thyroid nodules

\begin{tabular}{|c|c|c|}
\hline \multirow{2}{*}{ Elastography } & \multicolumn{2}{|c|}{ Fine needle aspiration cytology } \\
\cline { 2 - 3 } & Benign, $\mathrm{n}(\%)$ & Malignant, $\mathrm{n}(\%)$ \\
\hline Benign pattern (pattern 1+2) & $356(100)$ & 0 \\
\hline Malignant pattern (pattern 3+4) & $88(38.3)$ & $142(61.7)$ \\
\hline
\end{tabular}

Table 4: Statistics of elastography. (CI: Confidence interval, NPV: Negative Predictive value, PPV: Positive predictive value)

\begin{tabular}{|l|l|c|c|}
\hline & & Lower limit & Upper limit \\
\hline Sensitivity & $100 \%$ & 93.6 & 100 \\
\hline Specificity & $80.2 \%$ & 74.2 & 85.1 \\
\hline PPV & 61.7 & 52.2 & 70.5 \\
\hline NPV & $100 \%$ & 97.4 & 100 \\
\hline Accuracy & $85 \%$ & 80.4 & 88.9 \\
\hline
\end{tabular}


the sensitivity $92 \%$, and specificity $34 \%$ and positive predictive value (PPV) $85.4 \%$ and negative predictive value (NPV) $72.3 \%$ and accuracy $73 \%$. while evaluating benign and malignant lesions. In a local study ${ }^{19}$, ultrasound specificity, sensitivity, positive and negative predictive values, and accuracy for differentiating benign from malignant nodules were $93.2 \%, 93.8 \%, 81.1 \%, 98 \%$, and $93.3 \%$, respectively. Ragazzani et al, ${ }^{17}$ observed sensitivity of $85 \%$, specificity of $83.7 \%$, positive predictive value of $69.3 \%$ and negative predictive value of $92.7 \%$ while evaluating 77 out of 92 lesions as benign scored 1 0r 2 and 34 out of 40 lesions as malignant scored 3 or 4 . The sensitivity of $97.3 \%$ and specificity of $91.7 \%$ was observed in study done by Cantisani et al ${ }^{20}$ on elastography on 97 patients and observed the increased probability of malignancy in nodules having $>2$ strain ratio. In one study of Cantisani et al ${ }^{21}$ he reported more accuracy of elastography in comparison to color Doppler findings. Mansour and Schwebel ${ }^{22}$ observed sensitivity of $75.4 \%$, specificity of $85.5 \%$, positive predictive value of $71.4 \%$, negative predictive value of $90.5 \%$ and diagnostic accuracy of $86.7 \%$ and report that when used with high-resolution ultrasound, the diagnostic performance of elastography will improve.

Bojunga et al. ${ }^{23}$ conducted a meta-analysis of studies that distinguish benign and malignant thyroid nodules by evaluating real-time elastography and observed the significance of elastography for patient's candidates for surgery. With overall average sensitivity of $88-96 \%$ and specificity of $85-95 \%$ in a meta-analysis of 8 studies for 639 thyroid nodules proved high sensitivity and specificity for malignant nodules and excluded patients for invasive procedure which have elasticity score of 1 . The sensitivity of $100 \%$, specificity of $95 \%$, positive predictive value of $40 \%$ and negative predictive value of $100 \%$ was observed in study done by Akcay et al ${ }^{[24]}$ who used the ultrasound elastography technique to evaluate 110 nodules through the stiffness score and considered cutoff value of 4 for malignancy and achieved such sensitivity and specificity. This study also showed nodules with sore of 1 and 2 found to be benign while nodules with score of 3 and 4 found to be malignant. "Compared with studies in the literature, our research population is large." The sensitivity of $100 \%$, specificity of $80.2 \%$, positive predictive value of $61.7 \%$, negative predictive value of $100 \%$ and diagnostic accuracy of elastography is $85.0 \%$.

The main limitation is that the patient's definite diagnosis is made by fine needle aspiration cytology and not by surgical findings and histopathology which may have yield more accurate results and thus may have provided more sensitivity and specificity for elastography.

\section{CONCLUSION:}

Strain elastography is noninvasive technique which can be used to characterize thyroid nodules and helps in differentiating benign from malignant thyroid nodules and can limit the utilization of invasive technique like FNAC and helps in selection of patients which needs surgery.

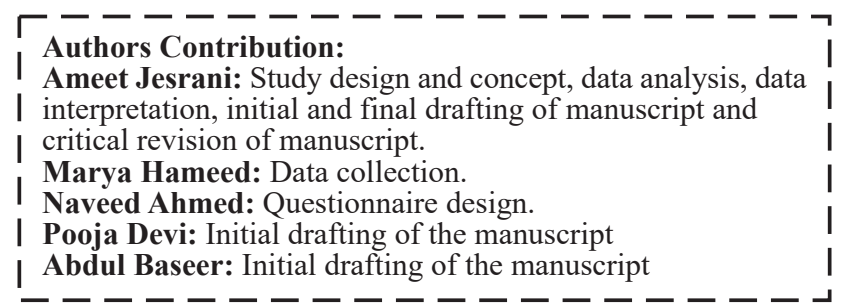

\section{REFERENCES:}

1. Tahmasebi M, Dezfouli MRB, Gharibvand MM, Jahanshahi A, Nikpour N, Rahim F. Diagnostic accuracy of sonography in assessment of thyroid masses in comparison with pathology. Russian Open Med J. 2016; 5: 103

2. Avinash B, Ahmed N, Sreedevi T, Swapna Ch, Latha RM, et al. Role of ultrasonography to differentiate benign and malignant thyroid nodules in correlation with fine-needle aspiration cytology. Int J Sci Stud. 2016; 4(5): 81-7.

3. Monpeyssen H, Tramalloni J, Poirée S, Hélénon O, Correas JM. Elastography of the thyroid. Diagn Interv Imaging. 2013;94:535-44.

4. Kwak JY, Kim EK. Ultrasound elastography for thyroid nodules: Recent advances. Ultrasonography. 2014;33:75-82.

5. Rubaltelli L, Corradin S, Dorigo A, Stabilito M, Tregnaghi A, Borsato S, et al. Differential diagnosis of benign and malignant thyroid nodules at elastosonography. Ultraschall Med. 2009;30:175-9.

6. Carneiro-Pla D. Ultrasound elastography in the evaluation of thyroid nodules for thyroid cancer. Curr Opin Oncol. 2013;25:1-5.

7. Azizi G, Keller J, Lewis M, Puett D, Rivenbark K, Malchoff C. Performance of elastography for the evaluation of thyroid nodules: A prospective study. Thyroid. 2013;23:734-40.

8. Reginelli A, Urraro F, di Grezia G, Napolitano G, Maggialetti $\mathrm{N}$, Cappabianca $\mathrm{S}$, et al. Conventional ultrasound integrated with elastosonography and B-flow imaging in the diagnosis of thyroid nodular lesions. Int J Surg. 2014;12(Suppl 1):S117-22.

9. Rago T, Santini F, Scutari M, Pinchera A, Vitti P. Elastography: New developments in ultrasound for predicting malignancy in thyroid nodules. J Clin Endocrinol Metab. 2007;92:2917-22.

10. Guazzaroni M, Spinelli A, Coco I, Del Giudice C, Girardi V, Simonetti G. Value of strain-ratio on thyroid real-time sonoelastography. Radiol Med. 2014;119:149-55.

11. Liu BX, Xie XY, Liang JY, Zheng YL, Huang GL, Zhou LY, et al. Shear wave elastography versus real-time elastography on evaluation thyroid nodules: A preliminary study. Eur J Radiol. 2014;83:1135-43.

12. Sahin M, Çakal E, Özbek M, Güngünes A, Arslan MS, Akkaymak ET, et al. Elastography in the differential diagnosis of thyroid nodules in Hashimoto thyroiditis. Med Oncol. 2014;31:97.

13. Xu JM, Xu HX, Xu XH, Liu C, Zhang YF, Guo LH, et al. Solid hypo-echoic thyroid nodules on ultrasound: The diagnostic value of acoustic radiation force impulse elastography. Ultrasound Med Biol. 2014;40:2020-30. 
14. Zhang FJ, Han RL. The value of acoustic radiation force impulse (ARFI) in the differential diagnosis of thyroid nodules. Eur J Radiol. 2013;82:e686-90.

15. Ko SY, Kim EK, Sung JM, Moon HJ, Kwak JY. Diagnostic performance of ultrasound and ultrasound elastography with respect to physician experience. Ultrasound Med Biol. 2014;40:854-63.

16. Cantisani V, Grazhdani H, Ricci P, Mortele K, Di Segni M, D'Andrea V, et al. Q-elastosonography of solid thyroid nodules: Assessment of diagnostic efficacy and interobserver variability in a large patient cohort. Eur Radiol. 2014;24:143-50.

17. Ragazzoni F, Deandrea M, Mormile A, Ramunni MJ, Garino F, Magliona G, et al. High diagnostic accuracy and interobserver reliability of real-time elastography in the evaluation of thyroid nodules. Ultrasound Med Biol. 2012;38:1154-62.

18. Afifi AH, Alwafa WAHA, Aly WM, Alhammadi HAB. Diagnostic accuracy of the combined use of conventional sonography and sonoelastography in differentiating benign and malignant solitary thyroid nodules. Alexandria J Med. 2017; 53: 21-30

19. Zahir ST, Vakili M, Ghaneei A, Sharahjin NS, Heidari F. Ultrasound assistance in differentiating malignant thyroid nodules from benign ones. J Ayub Med Coll Abbottabad. 2016; 28(4): 644-9.
20. Cantisani V, D'Andrea V, Biancari F, Medvedyeva O, Di Segni M, Olive M, et al. Prospective evaluation of multiparametric ultrasound and quantitative elastosonography in the differential diagnosis of benign and malignant thyroid nodules: Preliminary experience. Eur J Radiol. 2012;81:2678-83.

21. Cantisani V, D'Andrea V, Mancuso E, Maggini E, Di Segni M, Olive M, et al. Prospective evaluation in 123 patients of strain ratio as provided by quantitative elastosonography and multiparametric ultrasound evaluation (ultrasound score) for the characterisation of thyroid nodules. Radiol Med. 2013;118:1011-21.

22. Shweel M, Mansour E. Diagnostic performance of combined elastosonography scoring and high-resolution ultrasonography for the differentiation of benign and malignant thyroid nodules. Eur J Radiol. 2013;82:995-1001.

23. Bojunga J, Herrmann E, Meyer G, Weber S, Zeuzem S, Friedrich-Rust M. Real-time elastography for the differentiation of benign and malignant thyroid nodules: A meta-analysis. Thyroid. 2010;20:1145-50.

24. Akcay MA, Semiz-Oysu A, Ahiskali R, Aribal E. The value of ultrasound elastography in differentiation of malignancy in thyroid nodules. Clin Imaging. 2014;38:100-3 